\title{
AUTOMATED EXCAVATION PROCESS ANALYSIS FOR GIVEN TRAJECTORY AND SOIL PARAMETERS
}

\author{
Jarosław Kuśmierczyk \\ Institute of Construction Machinery Engineering \\ 84 Narbutta \\ 02-524 Warsaw, Poland \\ jkusmierczyk@simr.pw.edu.pl
}

\author{
Jan Szlagowski \\ Institute of Construction Machinery Engineering \\ 84 Narbutta \\ 02-524 Warsaw, Poland \\ jsz@simr.pw.edu.pl
}

\begin{abstract}
Since excavation process is very complex, it can be optimized in many ways, using different factors. In this paper excavation process optimization for backhoe excavator is presented. Results that are presented covers two scopes. First, relation between excavating force and tool angle of attack. Second is optimization of the bucket path. Reassuming, optimal trajectory, taking under consideration filling the bucket and minimal excavating force has been found.
\end{abstract}

\section{KEYWORDS}

automation, backhoe excavator, measurement, digging force

\section{INTRODUCTION}

Excavation process is main task of an excavator. Its proper parameters are very important due to economy and equipment lifetime. It is also crucial for efficiency. Resistive forces which arise during excavation process are very difficult to describe as far as their value and direction not to mention initial points. Mostly resistive forces are frictional forces. Results that are presented covers two scopes. First, relation between excavating force and tool angle of attack. Second is optimization of the bucket path.

\section{TEST RIG}

Test rig, consisting of excavator, ditch with soil and computer system, has been used to performed all necessary tests. The excavator - Warynski K-111 with bucket capacity of $0,1 \mathrm{~m} 3$ is placed $3 \mathrm{~m}$ over the ground on specially designed support (Figure 1). In front of excavator's support, the ditch is positioned. There is a soil prepared according to developed methodology inside the ditch. It is also possible to exchange the soil in the ditch, thanks to its modular design. Ditch capacity is approximately $17 \mathrm{~m}^{3}$. Soil inside the ditch witch weights around 28 tons. Knowing these numbers it easy to realize how big it is. The backhoe excavator works under control of computer system, which is based on OS-9 operating system and industrial computer. The given trajectory is replayed in fully automatic mode. Thanks to measurement system, which consists of pressure transducers (pressures are measured in all three 
hydraulic cylinders - both sides and after the pump), flow transducer (placed after the pump), force transducers in all three cylinder rods, linear displacement of three hydraulic cylinders it is possible to recorded a lot of data for further analysis. Collected data can be easily transferred to Microsoft Excel using specially design software.

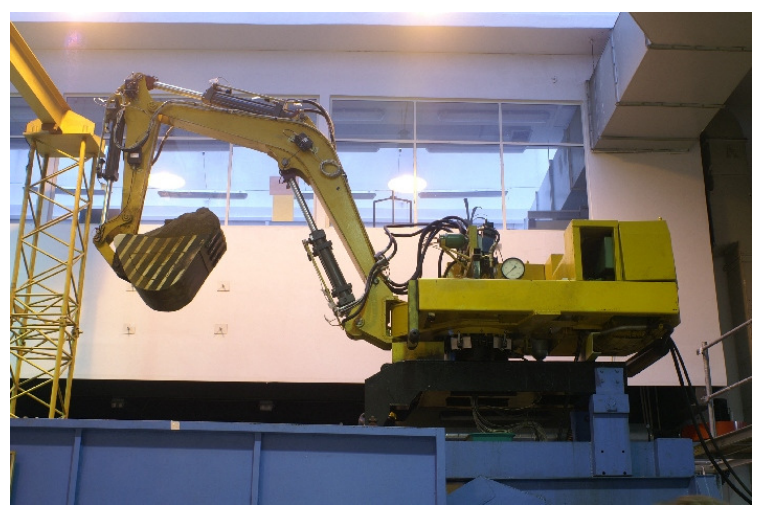

Figure 1. Test rig

\section{SOIL PREPARATION METHODOLOGY}

While the tests that were planned to perform were comparative tests we need to keep test's conditions unchanged. Trajectory path and soil parameters are meant to be unchanged. To conduct research over excavation process, homogeneous soil with constant parameters is needed. For that reason, the first step, was to develop soil and its preparation methodology. It this point it is very important to mention, that soil is just an environment not the aim of the tests. Our soil consists of gravel with known grain dimension (thanks to sieve analysis) and sand mixed with solution of water and special coolant which is used in machining process. This coolant is environmental friendly. Internal friction angle is 34 degrees. Using the coolant, soil parameters are kept stable for quite a long time, despite of humidity changes. Evaporation is phenomenon that cannot be eliminated, soil humidity is monitored constantly and when it is too low, certain solution is added. Water penetration is sped up using excavator performing several working cycles. Once soil was prepared, the correct preparation methodology was needed to obtain the same strength soil parameters for each test. It is very important since comparative tests should be performed. Methodology let us omit some very time-taking and laborious test such us dynamic cone penetration. Below, the procedure for soil preparation is presented:

After the test, it is necessary to remove some extra soil from the ditch, because the pit has to be extended. Next, the pit is covered with one layer of $15 \mathrm{~cm}$ of soil. Using compactor, it takes 7 rounds to compact the soil to the certain level. More rounds is not making the soil strengthener. It rather cause the soil to loose its strength.

After the layer is compacted, shear strength is measured by means of annular shear graph. Its advantages are: simplicity, short test time, test can be performed by one person. But it has also one disadvantage. It is impossible to measure soil strength after finishing whole preparation process. It can measure only layer's strength.

Points 2 to 4 should be repeated until whole pit is filled with soil. Procedure simplicity does not correspond to its time-taking character and laboriousness. Each layer is filled manually using special box carried by a gantry. Leveling and compacting is also done manually. All of this makes preparation methodology a really hard work. It takes 45 to 90 minute to prepare the soil for each test and it takes 5 to 15 minutes to perform the test. 90 minute preparation cycle takes place when there are trajectory with different depth replayed.

Methodology has been verified by means of two different methods. First, the dynamic cone penetration (result are given in the Figure 2a). Second method has been using excavator as a measurement device. The model trajectory path has been replayed several times. During these test forces in each hydraulic cylinder have been monitored and recorded. Than, using MS Excel they were analyzed (result are given in the Figure 2b)

Soil preparation before developing special methodology took 2 hours. When following the instruction, time was shorten to 1 hour. Simply it was shorten by $50 \%$. It means that we could conduct 2 or 3 test more per day. 


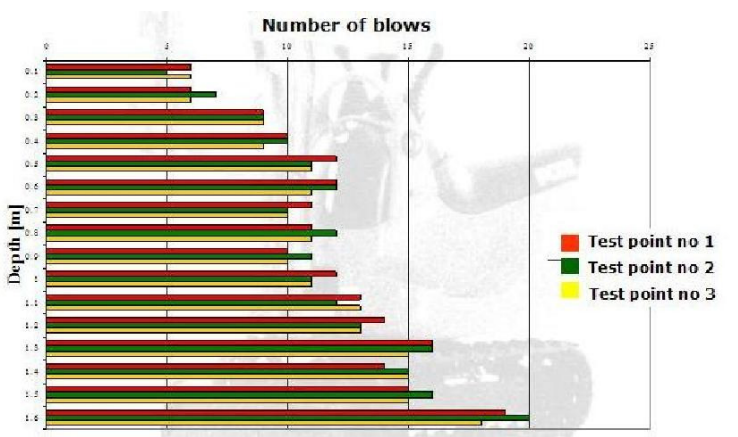

Figure 2a. Dynamic cone penetration results

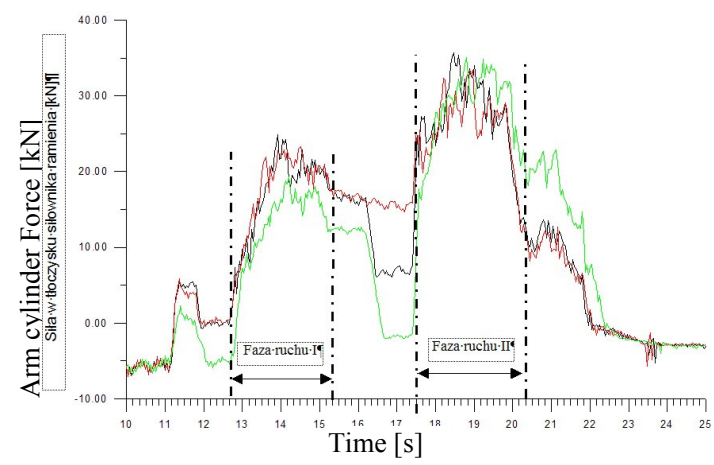

Figure 2b. Force in arm cylinder

\section{TOOL FOR TRAJECTORY VERIFICATION}

Main task of the issued research was to design specific tool trajectory path. On the other side the trajectory path is seen by algorithm of control system as numbers corresponding with piston rods displacement, swing angle, speeds and accuracy etc. The notation is not clear. In fact it is not easy to design trajectory by giving only numbers, which does not give any practical information. As practical information: position of the bucket in reference to ground level $\mathrm{z} 0$ and e.g. theoretical amount of excavate soil is understood. Reading trajectory notation, any information on rake angle cannot be given. That is why the tool for trajectory verification has been built. This is an application built on basis of Mechanical Desktop environment. Below main features are presented:

Visualization of excavator equipment position corresponding to displacement of hydraulic cylinders. At this point trajectory can be corrected in case it is not exactly corresponding with our expectations.

With this tool it is possible to generate path of bucket tooth during digging process.

1. The tool allows to determine theoretical amount of excavated soil by means of calculating area of path crossover. Of course it is a theoretical value. It does not consider amount of soil that is lost during last phase of the process.

2. By means of this tool value of angle of attack can be easily determined.

At this point it is very important to mention that presented tool has a very important role. It is nor for designing any trajectory. It is meant to design and analyze model trajectory which shape and parameters that suppose to provide information for excavator task resolving system. Below, typical tasks for trajectory verification tool are presented (Figure 3, 4).

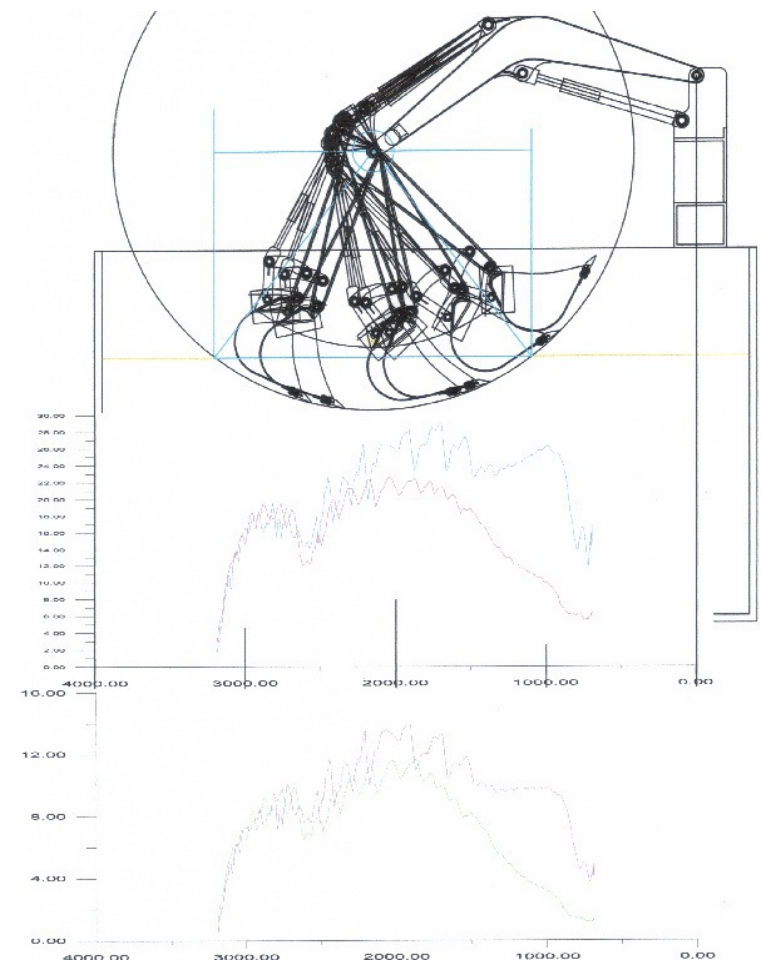

Figure 3. Excavation process analysis 


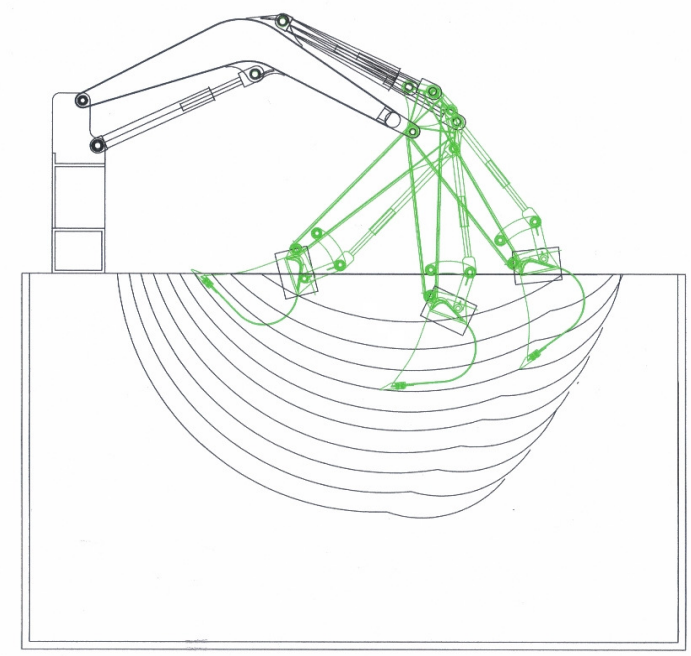

Figure 4. Group of trajectories in excavator working range

\section{RESEARCH PROGRAM}

Results presented below are just a small part of whole research program. Program that has been performing on presented test rig for the last two years. It must be said that each of the tests conducted has put a lot of questions for research team. Phenomena that have been encountered were well described in a literature, but there were no results of their experimental research. Results that are presented cover two scopes. First, relation between excavating force and tool angle of attack. Second, optimization of the bucket path. It should be pointed out that results are true only for given soil parameters and trajectory path.

\subsection{Optimization of angle of attack}

First group of research concerns relation between excavating force and tool angle of attack. Theoretical knowledge can be found in scientific publications e.g. [1]. Also in manuals for excavator operators information about rake angle or angle of attack can be found. It is very hard to find tests confirming this information. To verify that several trajectories have been prepared differ only by angle of attack. Model trajectory consists of five phases:
Setting equipment in the initial position (boom maximum displacement, arm and bucket - minimal displacement)

Lowering the equipment using only boom cylinder. Bucket teeth are supposed to reach ground level, called $\mathrm{z}_{0}$

Setting given angle of attack.

Excavating using only arm cylinder.

Closing the bucket and raising the equipment.

It can be seen that force we are interested in is the force acting on arm cylinder piston rod. As a result relation between excavating force and tool angle of attack has been determined. It can be seen that minimal $\left(0^{0}\right)$ rake angle does not give minimal excavating force. Optimal rake angle in case of soil parameters, trajectory and tool shape is $9^{0}$. Below, obtained results has been presented (Figure 5).

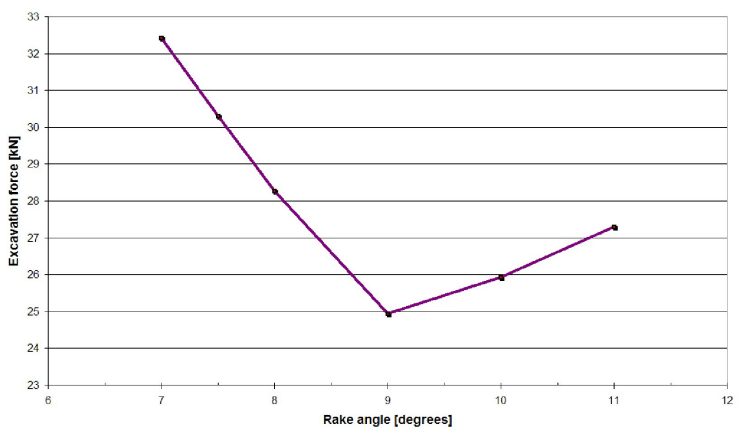

Figure 5. Relation between excavating force and tool angle of attack

\subsection{Trajectory}

Second group of research concerns optimization of bucket path. This is a very important issue if looking from efficiency point of view. Trajectory designing process has been described in literature [2-7]. At the beginning our tests mainly have concerned optimal angle of attack. But as we collected more and more data we have found that the bucket was not properly filled with soil, which at the end of the process was push in front of it. It means higher energy losses and higher value of forces acting on the equipment. We have decided to slightly change the trajectory at the end of excavation phase. All we did, was analyse 
whole process using tool for trajectory verification and decide when to close the bucket. Optimization was performed only for trajectory for which excavation force had minimal value. Modified trajectory caused drop of equipment load and improved bucket filling. Below change in shape and change in force character are presented (Figure 6,7). Red line named "FbR [kN] przed" represents force in arm cylinder before optimization. Dark yellow line named "FbR $[\mathrm{kN}]$ po" represents force in arm cylinder after optimization. Light green line named "FbL $[\mathrm{kN}]$ przed" represents force in bucket cylinder before optimization. Dark green line named "FbL $[\mathrm{kN}]$ po" represents force in bucket cylinder after optimization. Blue and yellow lines represents accordingly linear displacement of bucket cylinder and arm cylinder.

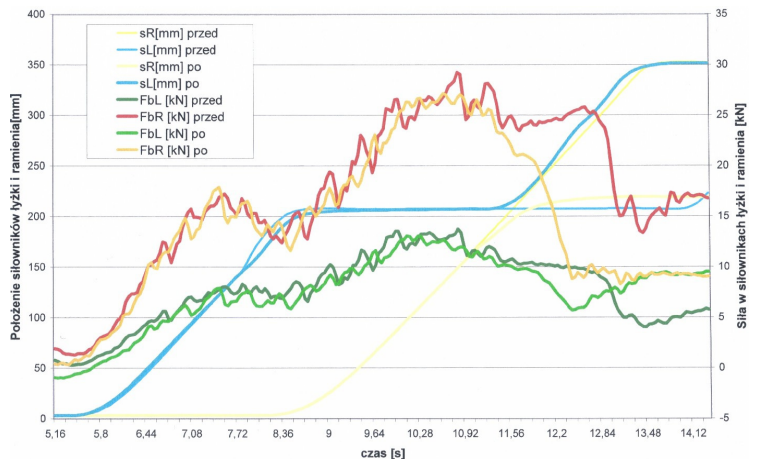

Figure 6. Change in force character

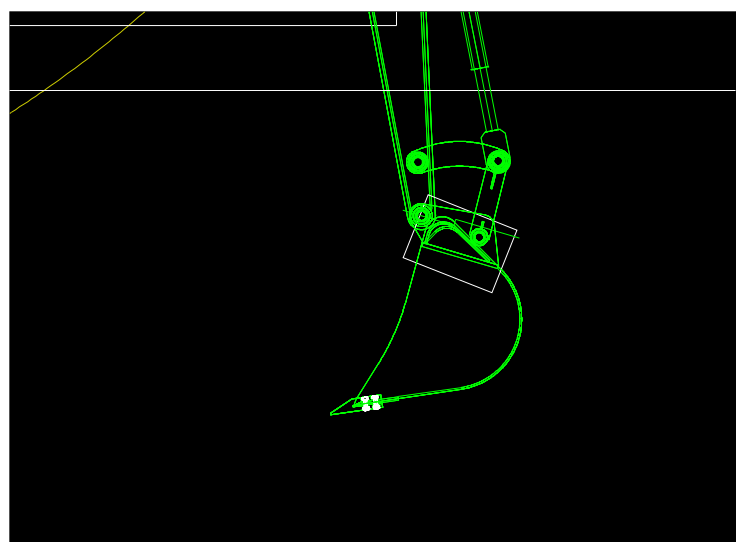

Figure 7. Change in shape of trajectory

\section{SUMMARY}

Conducted test has verified test rig to be very useful in performing comparable tests. Automatic control of the bucket movement and measurement system based on industrial computer has given us possibility to replay any trajectory, with given accuracy, as many times as it was needed. Developed soil preparation methodology has turned to be crucial for success. Reassuming, optimal trajectory, taking under consideration filling the bucket and minimal excavating force has been found.

\section{REFERENCES}

[1] Brach I., Walczewski R., (1982). Koparki jednonaczyniowe, WNT, Warszawa.

[2] Budny E., Chłosta M., Gutkowski W., (1999). Optymalna droga łyżki koparki, Materiały XII Konferencji Naukowej PRMR, Zakopane.

[3] Cendrowicz J., Płonecki L., (1995). Planowanie trajektorii narzędzia skrawającego koparki z wykorzystaniem krzywych Beziera, Przegląd Mechaniczny 19/95, Warszawa.

[4] Cendrowicz J., Gierulski W., Płonecki L., Trąmpczyński W., Sokołowski K., (1999). Optymalne energetycznie trajektorie narzędzia $\mathrm{w}$ procesie urabiania łyżką koparki i ich generowanie $\mathrm{z}$ użyciem automatycznego systemu sterowania, XII Konferencja Naukowa Problemy Rozwoju Maszyn Roboczych, Zakopane.

[5] Praca zbiorowa, Problemy automatyzacji pracy maszyn roboczych. MET Warszawa, 2000.

[6] Seward, D. W. And Quayle, S., (1997). Lucie Lancaster University computerised intelligent excavator.

[7] Sanjiv S., (1995). Synthesis of Tactical Plans for Robotic Excavation, Carnegie Mellon University, Pittsburgh. 